Sleep and sleepiness in shift-working tram drivers

\title{
Onninen, Jussi
}

2020-10

Onninen , J , Hakola , T , Puttonen , S , Tolvanen , A , Virkkala , J \& Sallinen , M 2020 , '

Sleep and sleepiness in shift-working tram drivers ' , Applied Ergonomics , vol. 88 , 103153 . https://doi.org/10.1016/

http://hdl.handle.net/10138/333354

https://doi.org/10.1016/j.apergo.2020.103153

publishedVersion

Downloaded from Helda, University of Helsinki institutional repository.

This is an electronic reprint of the original article.

This reprint may differ from the original in pagination and typographic detail.

Please cite the original version. 


\title{
Corrigendum to 'Sleep and sleepiness in shift-working tram drivers' [Applied Ergonomics Sleep and sleepiness in shift-working tram drivers 88 (2020) 103153]
}

\author{
Jussi Onninen $^{\mathrm{a}, \mathrm{b}, *}$, Tarja Hakola ${ }^{\mathrm{b}}$, Sampsa Puttonen ${ }^{\mathrm{b}}$, Asko Tolvanen ${ }^{\mathrm{a}}$, Jussi Virkkala ${ }^{\mathrm{b}, \mathrm{c}}$, \\ Mikael Sallinen ${ }^{\mathrm{a}, \mathrm{b}}$ \\ ${ }^{a}$ Department of Psychology, University of Jyväskylä, Jyväskylä, Finland \\ ${ }^{\mathrm{b}}$ Finnish Institute of Occupational Health, Helsinki, Finland \\ ${ }^{\mathrm{c}}$ Department of Clinical Neurophysiology, University of Helsinki and Helsinki University Hospital, Helsinki, Finland
}

The authors regret to have omitted to mention the study of Pylkkönen et al. Sleepiness, sleep, and use of sleepiness countermeasures in shift-working long-haul truck drivers (Accident Analysis and Prevention. 2015 July; 80:201-10. doi: 10.1016/j.aap.2015.03.031) as a reference for the classification of on-duty sleepiness countermeasures presented in Table 1.

The authors would like to apologise for any inconvenience caused.

DOI of original article: https://doi.org/10.1016/j.apergo.2020.103153.

* Corresponding author. Department of Psychology, University of Jyväskylä, Jyväskylä, Finland

E-mail address: jussi.onninen@jyu.fi (J. Onninen). 